\title{
PENYEDIAAN PAKAN ALAMI UNTUK MENINGKATKAN SINTASAN DAN PERTUMBUHAN LARVA IKAN RAINBOW KURUMOI (Melanotaenia parva)
}

\author{
Tutik Kadarini\#, Siti Zuhriyyah Musthofa, dan Mochammad Zamroni \\ Balai Riset Budidaya Ikan Hias \\ Jl. Perikanan No. 13, Pancoran Mas, Depok 16436
}

(Naskah diterima: 4 September 2018; Revisi final: 6 November 2018; Disetujui publikasi: 6 November 2018)

\begin{abstract}
ABSTRAK
Permasalahan utama budidaya ikan rainbow (M elanotaenia parva) adalah sintasan larva yang masih rendah terutama pada saat terjadi peralihan makan dari cadangan kuning telur (endogenous) ke pakan eksternal (eksogenous). Pakan awal larva rainbow berupa pakan alami (plankton). Untuk menyediakan plankton dapat dilakukan melalui pemupukan kotoran ayam. Tujuan penelitian adalah penyediaan pakan alami untuk meningkatkan sintasan dan pertumbuhan larva ikan rainbow kurumoi melalui pemupukan kotoran ayam dengan dosis yang berbeda di akuarium. Akuarium yang digunakan berukuran $50 \mathrm{~cm} \times 50 \mathrm{~cm} \times 40 \mathrm{~cm}$ sebanyak 15 buah dengan volume air $40 \mathrm{~L}$. Dosis pupuk kotoran ayam yang diujikan sebagai berikut: (A) kontrol (tanpa pemupukan), (B) $5 \mathrm{~g}$, (C) $10 \mathrm{~g}$, (D) $15 \mathrm{~g}$, dan (E) $20 \mathrm{~g}$ per $40 \mathrm{~L}$ air, masing-masing perlakuan diulang tiga kali. Ikan uji yang digunakan berupa larva rainbow kurumoi yang berumur dua hari. Larva ditebar setelah 5-7 hari pemupukan dengan kepadatan sebanyak 100 ekor/wadah. Rancangan percobaan yang digunakan rancangan acak lengkap (RAL). Parameter yang diamati unsur hara pupuk, jenis dan kelimpahan plankton, sintasan larva, pertumbuhan (panjang dan bobot) larva, dan kualitas air. Hasil penelitian menunjukkan bahwa pemupukan kotoran ayam terbaik dengan dosis pupuk $20 \mathrm{~g} / 40 \mathrm{~L}$ dengan kelimpahan plankton 58.300 ind./L; sintasan larva 84,33 \pm 3,79\% dan pertumbuhan (bobot 0,048 \pm 0,012 g; panjang total $1,67 \pm 0,15 \mathrm{~cm}$ dan panjang standar $1,44 \pm 0,13 \mathrm{~cm}$ ).
\end{abstract}

\section{KATA KUNCl: pupuk; larva M elanotaenia parva; plankton; sintasan}

ABSTRACT: The provision of natural food to improve the survival and growth of rainbow kurumoi larvae (Melanotaenia parva). By: Tutik Kadarini, Siti Zuhriyyah Musthofa, and Mochammad Zamroni

The main problem of rainbow aquaculture is the survival of larvae which is still low, especially at the time of the initial eating, namely the transition of food endogenous to exogenous. The initial feed of rainbow larvae is natural food (plankton). To provide natural food can be done through fertilization chicken manure. The aim of the study was the provision of natural food to improve the survival and growth of rainbow kurumoi larvaeby fertilizing chicken manure with different doses in the aquarium. The container used is $50 \mathrm{~cm} \times 50 \mathrm{~cm} \times 40 \mathrm{~cm}$ aquarium with 15 pieces with 40 $\mathrm{L}$ water volume. The doses of chicken manure were tested as follows (A) control (without fertilization), (B) $5 \mathrm{~g}$ (C) 10 $g$, (D) $15 \mathrm{~g}$ and (E) $20 \mathrm{~g}$ per container where each treatment was repeated 3 times. The test fish used were rainbow kurumoi larvae that were around 1-2 days old. Larvae are stocked after fertilizing around 5-7 days with a density of 100 larvae/container. The experimental design was a completely randomized design (CRD). Parameters observed were fertilizer nutrients, type and abundance of plankton, larvae survival, growth (length and weight) of larvae and water quality. The results showed that fertilizing the best chicken manure with a fertilizer dose of $20 \mathrm{~g} / 40 \mathrm{~L}$ with an abundance of plankton 58,300 ind./L, survival $84.33 \pm 3.79 \%$ and growth (weight $0.048 \pm 0.012 \mathrm{~g}$, total length $1.67 \pm 0.15 \mathrm{~cm}$ and standard length $1.44 \pm 0.13 \mathrm{~cm}$ ).

KEYWORDS: fertilizer; rainbow larvae; plankton; survival rate

\footnotetext{
\# Korespondensi: Balai Riset Budidaya Ikan Hias.

Jl. Perikanan No. 13, Pancoran Mas, Depok 16436, Indonesia.

Tel. + 62217520482

E-mail: tutikdarso@gmail.com
} 


\section{PENDAHULUAN}

Sekitar 75 spesies ikan rainbow ditemui menyebar di kawasan Papua, Sulawesi, dan Australia (Tappin, 2011). Spesies ikan rainbow yang ditemukan di Papua di antaranya yaitu rainbow boesmani (Melanotaenia boesmani), rainbow merah (Glossolepis incisus), dan rainbow kurumoi (Melanotaenia parva). Ikan rainbow kurumoi merupakan salah satu jenis ikan endemik Papua Barat tepatnya di Danau Kurumoi Kabupaten Bintuni. Ikan ini rentan kepunahan (vulnerable) berdasarkan data Red List International Union for Conservation and Natural Resources(IUCN) tahun 2016. Ancaman kepunahan disebabkan degradasi lingkungan berupa pendangkalan Danau Kurumoi dan masuknya ikan-ikan introduksi seperti ikan nila (Oreocromis mossambicus) yang menjadi predator terhadap telur dan larva ikan rainbow kurumoi (Kadarusman et al., 2010). Upaya untuk mengatasi ancaman kepunahan ikan rainbow kurumoi adalah melalui domestikasi. Salah satu tahapan dalam domestikasi adalah pembenihan pada lingkungan ex-situ. Permasalahan utama dalam pembenihan ikan rainbow kurumoi yaitu sintasan larva rendah pada umur sekitar 2-3 hari di mana terjadi peralihan makan endogenous ke eksogenous. Sintasan larva dapat ditingkatkan melalui penyediaan pakan alami dengan pemupukan pada media pemeliharaan larva. Telur ikan rainbow kurumoi menetas setelah 6-7 hari pada suhu $25-28,5^{\circ} \mathrm{C}$ (Kadarini et al., 2013). Bukaan mulut larva berumur 1-4 hari berkisar 0,081-0,094 mm. Jenis pakan alami untuk larva rainbow berupa plankton yang jenisnya Infusoria $(0,090-0,110 \mathrm{~mm})$ atau Rotifera $(0,090-0,300 \mathrm{~mm})$ (Segers, 1995 dalam Lucas \& Southgate, 2003).

Plankton dapat hidup dan berkembang bila ada unsur hara nitrogen, fosfat, dan kalsium (NPK). Salah satu jenis pupuk yang umum digunakan berupa kotoran ayam karena pupuk ini murah dan mudah penyediaannya. Pemupukan dengan menggunakan kotoran ayam di kolam pemeliharaan benih balashark berpengaruh terhadap ketersediaan pakan alami sehingga mampu meningkatkan sintasan dan pertumbuhan lebih tinggi dibandingkan dengan pemupukan menggunakan pupuk cair komersial maupun pupuk padat komersial (Insan, 2011). Larva ikan rainbow kurumoi berumur 2 hari yang dipelihara selama satu bulan dan diberi pakan artemia dengan frekuensi 3 kali sehari menghasilkan sintasan sebesar 45\%(Subandiyah et al., 2011).

Penggunaan pupuk kotoran ayam di akuarium untuk menumbuhkan pakan alami belum banyak diteliti. Pada penelitian ini dilakukan pengujian penggunaan pupuk kotoran ayam pada berbagai dosis pada media pemeliharaan larva ikan rainbow kurumoi di akuarium. Tujuan penelitian ini yaitu untuk menentukan dosis pemupukan yang tepat dapat meningkatkan pertumbuhan plankton, sintasan, dan pertumbuhan larva, serta mempertahankan kualitas air media pemeliharaan. Dengan dosis pupuk yang tepat plankton bisa tumbuh dengan optimal tetapi tidak menurunkan kualitas air yang dapat mematikan larva dalam akuarium.

\section{BAHAN DAN METODE}

\section{Produksi Larva}

Penelitian dilakukan di Laboratorium Balai Riset Budidaya Ikan Hias (BRBIH) Depok selama 3 bulan. Induk generasi ketiga berukuran sekitar $5-7 \mathrm{~cm}$ sebanyak 50 ekor dipijahkan secara alami dan massal dengan rasio jantan betina 2:3. Larva ikan rainbow kurumoi yang berumur sekitar dua hari berukuran panjang 0,4$0,5 \mathrm{~cm}$ digunakan sebagai ikan uji. Larva dipelihara selama satu bulan di akuarium berukuran $50 \mathrm{~cm} \times 50$ $\mathrm{cm} \times 40 \mathrm{~cm}$ sebanyak 15 buah dengan volume air 40 liter yang dilengkapi aerasi dan lampu neon 10 watt sebagai sumber cahaya. Padat tebar larva yaitu 100 ekor/akuarium.

\section{Perlakuan}

Sebelum larva ditebar, air media dipupuk kotoran ayam dengan kadar air 20\% Dosis pupuk yang diujikan yaitu: (A) kontrol (tanpa pemupukan), (B) $5 \mathrm{~g}$ (C) $10 \mathrm{~g}$, (D) $15 \mathrm{~g}$, dan (E) $20 \mathrm{~g}$ per $40 \mathrm{~L}$ air dan masing-masing perlakuan diulang tiga kali. Setelah media dipupuk dengan kotoran ayam, dilakukan inokulasi plankton yang diambil dari kolam beton sebanyak sekitar 3.500 ind./wadah yang terdiri atas 13 genus fitoplankton (Cyclotella, M elosira, Nitzchia, Characium, Chlorella, Coelastrum, Pediastrum, Protococcus, Rhapidium, Scenedesmus, Tabellaria, Aphanocapsa, dan Microcystis) dan 4 genus dari Zooplankton (Diaphanosoma, Moina, Branchionus, dan Testudinella). Adapun inokulasi plankton dilakukan pada waktu yang sama pukul 09.00 untuk semua perlakuan baik yang tidak dipupuk maupun yang dipupuk.

Larva ditebar 5-7 hari setelah inokulasi plankton. Penambahan pakan dilakukan apabila plankton yang tumbuh di akuarium telah habis atau berkurang yang ditandai dengan warna media menjadi bening. Pada larva berumur $>20$ hari diberi tambahan plankton yang didominasi jenis moina.

Parameter yang diamati antara lain unsur hara NPK dari kotoran ayam, identifikasi dan kelimpahan plankton, sintasan larva, pertumbuhan larva, dan kebiasaan pakan larva serta kualitas air yang meliputi pH, suhu, oksigen, kesadahan, dan amonia. Untuk mengetahui jenis plankton yang dimakan larva dilakukan dengan menganalisa isi perut larva. Kelimpahan plankton 
dianalisa hanya sekali yaitu sekitar 7 hari setelah pemupukan. Rumus kelimpahan plankton (Sachlan, 1982) sebagai berikut:

$$
\text { Faktor pengali }=\frac{\text { Vol. terkonsentrasi }}{\text { Vol. yang dihitung }} \times 1 \mathrm{~L} \text { Vol. yang disaring }
$$

\section{HASIL DAN BAHASAN}

Hasil analisa unsur hara dari pupuk organik (kotoran ayam) dengan dosis yang berbeda disajikan pada Tabel 1. Nilai NPK di media bertambah seiring dengan bertambahnya dosis pupuk dan yang tertinggi $20 \mathrm{~g} / 40$ L. Hasil analisa unsur hara yang paling tinggi $\mathrm{K}$, berikutnya $\mathrm{N}$, dan yang terakhir $\mathrm{P}$.

\section{Kelimpahan Plankton di Media}

Hasil pengamatan identifikasi dan kelimpahan plankton pada media pemeliharaan larva yang diberi pupuk kotoran ayam dosis $20 \mathrm{~g} / 40 \mathrm{~L}$ diperoleh sebanyak 20 genus yang terbagi ke dalam 14 genus dari fitoplankton dan 6 genus dari zooplanktondalam hal ini lebih tinggi bila dibanding dosis pupuk $10 \mathrm{~g} / 40$ $L$ diperoleh sebanyak 18 genus yang terbagi ke dalam 12 genus dari fitoplankton dan 6 genus zooplankton (Tabel 2). Identifikasi dan kelimpahan plankton pada dosis 5 dan $15 \mathrm{~g} / 40 \mathrm{~L}$ tidak dilakukan karena dari dua perlakuan dosis 10 dan $20 \mathrm{~g} / 40 \mathrm{~L}$ sebagai sampel mewakili perlakuan lainnya. Hasil identifikasi memberi gambaran bahwa plankton dapat tumbuh diakuarium yang dipupuk dengan kotoran ayam dan kelimpahan meningkat seiring dosis pupuk (Tabel 2).

Crustacea dan rotifera termasuk zooplankton dari kelas yang berbeda (ITIS, 2018). Fitoplankton akan dimanfaatkan oleh organisme lainnya termasuk zooplankton (Asriyana \& Yuliana, 2012). Rotifera bersifat omnivora, jenis makanannya terdiri atas perifiton, nanoplankton, detritus, semua partikel organik yang sesuai lebar mulut dan yang paling efisien
Chlorophyceae (alga hijau) (Redjeki, 1999). Kelimpahan zooplankton yang teridentifikasi selama penelitian lebih sedikit dibanding dengan fitoplankton dikarenakan sebagian terutama genus Rotifera dimakan oleh larva.

Selain itu rendahnya zooplankton pada penelitian ini karena analisa plankton sekitar tujuh hari setelah inokulasi. Siklus zooplankton lebih lama sekitar tujuh hari dibanding fitoplankton sekitar empat hari (Utomo et al., 2005; Astiani et al., 2016).

\section{Plankton dalam Saluran Pencernaan}

Kebiasaan pakan larva ikan rainbow kurumoi dilakukan dengan mengidentifikasi dan menghitung jumlah plankton dalam saluran pencernaan. larva yang diidentifikasi adalah yang berasal dari perlakuan 10 $\mathrm{mg} / 40 \mathrm{~L}$ dan $20 \mathrm{mg} / 40 \mathrm{~L}$. Hasil analisis menunjukkan bahwa dalam saluran pencernaan larva teridentifikasi 10 genus plankton dari 20 genus yang ada di media (Tabel 3).

Hal ini dapat dikatakan bahwa tidak semua genus plankton yang berada dalam akuarium pemeliharaan dimanfaatkan oleh larva rainbow kurumoi, dikarenakan di antaranya berkaitan bukaan mulut larva rainbow kurumoi yang masih kecil dan juga jenis pakan alami. Larva ikan rainbow kurumoi berumur 210 hari cenderung berenang di permukaan air begitu juga rotifera pada pagi berada di permukaan air dan tidak banyak bergerak sehingga mudah dimangsa oleh larva. Dengan melihat kriteria tersebut, dapat dikategorikan bahwa genus rotifera dan kelas Bacillariophyceae merupakan pakan utama bagi larva rainbow kurumoi, karena jumlah plankton lebih dari $25 \%$ maka larva rainbow kurumoi dikategorikan termasuk ke dalam ikan omnivora. Saluran pencernaan larva yang telah dibedah dan diidentifikasi plankton (Gambar 1).

Tabel 1. Kandungan unsur hara nitrogen, fosfat, dan kalium dari pupuk kotoran ayam dengan dosis berbeda

Table 1. Nitrogen, phosphate, and kalium content in chicken manure as fertilizer with different dosages

\begin{tabular}{cccc}
\hline \multirow{2}{*}{ Dosis (Dosis) $\mathbf{g} / \mathbf{4 0}$ L) } & \multicolumn{3}{c}{ Unsur hara kotoran ayam (Nutrient chicken manure) (\%) } \\
\cline { 2 - 4 } & Nitrogen (Nitrogen) & Posfat (Phosphate) & Kalium (Kalium) \\
\hline Kontrol (Control) & $<0,01 \pm 0.001^{\mathrm{a}}$ & $0,07 \pm 0.002^{\mathrm{a}}$ & $0,11 \pm 0.001^{\mathrm{a}}$ \\
5 & $3.41 \pm 0.07^{\mathrm{b}}$ & $1.17 \pm 0.07^{\mathrm{b}}$ & $6.70 \pm 0.31^{\mathrm{b}}$ \\
10 & $3.51 \pm 0.21^{\mathrm{b}}$ & $2.09 \pm 0.08^{\mathrm{c}}$ & $11.41 \pm 0.38^{\mathrm{c}}$ \\
15 & $5.85 \pm 0.68^{\mathrm{c}}$ & $3.62 \pm 0.22^{\mathrm{d}}$ & $17.93 \pm 0.75^{\mathrm{d}}$ \\
20 & $5.61 \pm 0.50^{\mathrm{c}}$ & $4.66 \pm 0.17^{\mathrm{e}}$ & $21.92 \pm 0.61^{\mathrm{e}}$ \\
\hline
\end{tabular}

Huruf supersript yang berbeda pada kolom yang sama menunjukkan berbeda nyata $(P<0,05)$

Different superscripts in the same colomn indicate significant difference $(p<0.05)$ 
Tabel 2. Hasil identifikasi dan kelimpahan plankton selama 7 hari pada dosis pupuk $10 \mathrm{~g} / 40 \mathrm{~L}$ dan $20 \mathrm{~g} / 40 \mathrm{~L}$

Table 2. Results of identification and abundance of plankton for 7 days at $10 \mathrm{~g} / 40 \mathrm{~L}$ and $20 \mathrm{~g} / 40 \mathrm{~L}$ fertilizer dosages

\begin{tabular}{|c|c|c|c|c|c|}
\hline \multirow{2}{*}{ Plankton } & \multirow{2}{*}{ Kelas (Class) } & & \multirow{2}{*}{ Marga (Genus) } & \multicolumn{2}{|c|}{ Dosis pupuk (Fertilizer dosages) } \\
\hline & & & & $10 \mathrm{~g} / 40 \mathrm{~L}$ & $20 \mathrm{~g} / 40 \mathrm{~L}$ \\
\hline Fitoplankton & Bacillariophyceae & 1 & Cyclotella & 700 & 6,600 \\
\hline \multirow[t]{17}{*}{ (Phytoplankton) } & & 2 & Melosira & 2,800 & 6,200 \\
\hline & & 3 & Nitzchia & 2,100 & 3,700 \\
\hline & & & $\sum$ Bacillariophyceae & 5,600 & 16,500 \\
\hline & Chlorophyceae & 1 & Characium & 3,200 & 4,300 \\
\hline & & 2 & Chlorella & - & 400 \\
\hline & & 3 & Coelastrum & 1,000 & 1,400 \\
\hline & & 4 & Pediastrum & 500 & 1,200 \\
\hline & & 5 & Protococcus & 1,400 & 1,300 \\
\hline & & 6 & Rhapidium & - & 600 \\
\hline & & 7 & Scenedesmus & 1,300 & 1,900 \\
\hline & & 8 & Tabellaria & 3,800 & 4,100 \\
\hline & & & $\sum$ Chlorophyceae & 11,200 & 15,200 \\
\hline & Cyanophyceae & 1 & Aphanocapsa & 1,100 & 1,500 \\
\hline & & 2 & Microcystis & 1,100 & 1,800 \\
\hline & & 3 & Oscillatoria & - & 600 \\
\hline & & & $\sum$ Cyanophyceae & 2,200 & 3,900 \\
\hline & & & $\sum$ Fitoplankton & 19,000 & 35,600 \\
\hline \multirow[t]{9}{*}{ Zooplankton } & Crustacea & 1 & Cyclops & 3,600 & 5,800 \\
\hline & & 2 & Diaphanosoma & 700 & 1,700 \\
\hline & & 3 & Moina & 6,800 & 6,500 \\
\hline & & 4 & Nauplius cyclops & 800 & 2,400 \\
\hline & & & $\sum$ Crustacea & 11,900 & 16,400 \\
\hline & Rotifera & 1 & Branchionus & 2,500 & 4,900 \\
\hline & & 2 & Testudinella & 400 & 1,400 \\
\hline & & & $\sum$ Rotifera & 2,900 & 6,300 \\
\hline & & & ¿Zooplankton & 13,800 & 22,700 \\
\hline \multicolumn{4}{|c|}{$\sum$ Fitoplankton \& Zooplankton ( $\Sigma$ Phytoplankton \& Zooplankton) } & 33,800 & 58,300 \\
\hline
\end{tabular}

Tabel 3. Identifikasi jenis dan jumlah plankton (\% yang teridentifikasi dalam saluran pencernaan larva ikan rainbow kurumoi

Table 3. Type identification and number of plankton (\%) identified in the digestive tract of rainbow kurumoi larvae

\begin{tabular}{llc}
\hline \multicolumn{1}{c}{ Kelas (Class) } & \multicolumn{1}{c}{ Jenis (Genus) } & $\%$ \\
\hline Bacillariophyceae & Cyclotella, Melosira dan Nitzchia & 30.90 \\
Chlorophyceae & Characium, Scenedesmusdan Tabellaria & 2.29 \\
Cyanophyceae & Aphanocapsa & 3.22 \\
Crustacea & anak moina & 0.23 \\
Rotifera & Branchionus dan Testudinella & 63.36 \\
\hline
\end{tabular}

\section{Sintasan dan Pertumbuhan}

Sintasan larva paling tinggi adalah pada dosis pupuk $20 \mathrm{~g} / 40 \mathrm{~L}(84,33 \% \pm 3,78 \%)$. Hal ini dikarenakan kelimpahan rotifera paling tinggi sehingga peluang larva untuk mendapatkan pakan lebih banyak.
Akibatnya sintasan larva paling tinggi dibanding perlakuan lainnya.

Sintasan larva paling rendah 46,67 $\pm 3,21 \%$ adalah pada perlakuan kontrol atau yang tidak ada pemupukan. Rendahnya sintasan pada perlakuan ini 

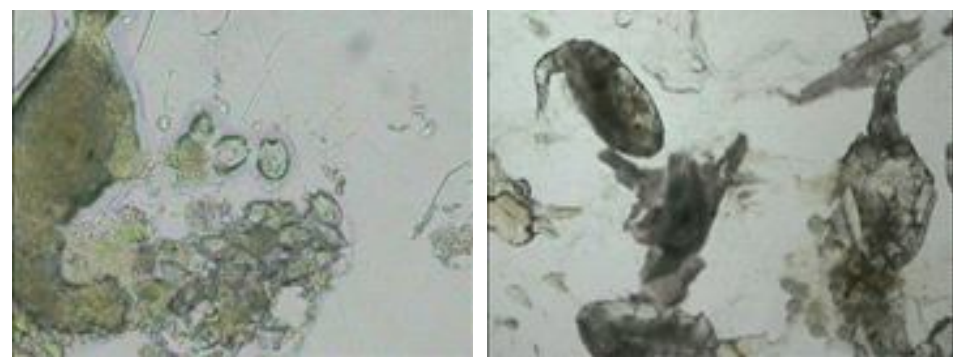

Gambar 1. Genus plankton yang ada di dalam saluran pencernaan larva ikan rainbow kurumoi (M elanotaenia parva).

Figure 1. Genus plankton obtained in digestive tract of rainbow kurumoi larvae (M elanotaenia parva).

dikarenakan saat plankton diberikan dalam kondisi hidup tidak mampu bertahan lama di media pemeliharaan maka sebagian plankton sudah mati sebelum dimakan oleh larva. Dalam kondisi ini bagi larva yang tidak mendapatkan makan akan mati yang akhirnya sintasan rendah. Menurut Kadarini et al. (2012), bahwa setelah telur menetas menjadi larva kemudian pada saat kuning telur dalam tubuh habis, larva memperoleh makanan dari luar tubuhnya. Masa peralihan untuk mendapatkan makan dari luar ini dikenal masa kritis. Dalam masa ini terjadi kematian yang sangat tinggi, penyediaan pakan yang memenuhi syarat bagi larva merupakan upaya yang tepat untuk mengatasi masa kritis pada larva umur tiga hari adalah saat larva pertama makan di mana kondisi mata yang belum sempurna dan sirip belum tumbuh sehingga gerakan larva yang masih terbatas (Kadarini et al., 2013).

Pertumbuhan larva ikan rainbow terbaik pada dosis $20 \mathrm{~g} / 40 \mathrm{~L}$, nilai rata-rata bobot $0.048 \pm 0.012 \mathrm{~g}$, panjang total $1.67 \pm 0,15 \mathrm{~cm}$ dan panjang standar $1.44 \pm 0.13 \mathrm{~cm}$ (Tabel 4). Pertumbuhan bobot dan panjang meningkat seiring dengan meningkatnya dosis pupuk dan kelimpahan rotifera. Kelimpahan rotifera paling tinggi maka peluang larva makan semakin besar yang akhirnya pertumbuhan tinggi selain sintasannya.

\section{Kualitas Air}

Kualitas air pada media pemeliharaan selama penelitian berlangsung disajikan pada Tabel 5 .

Kadar oksigen terlarut (DO) berkisar 3,8-4,91 mg/ $\mathrm{L}$ dan kisaran ini dapat ditoleransi oleh larva. Kisaran oksigen dihabitat alami untuk ikan rainbow kurumoi 5-8 mg/L (Tappin, 2010). Oksigen dimanfaatkan oleh ikan untuk metabolisme dan juga oleh mikroba untuk mengoksidasi bahan organik di antaranya pupuk. Efek langsung $\mathrm{pH}$ akan mempengaruhi kesetimbangan air sebagai media ikan dan larva akan mati ketika lingkungan $\mathrm{pH}$ berubah ekstrim atau berubah dengan cepat (Boyd, 1990). Derajat keasaman ( $\mathrm{pH}$ ) masih dalam kisaran untuk mendukung kehidupan larva. Ikan rainbow menyukai perairan dengan $\mathrm{pH}$ cenderung basa. Ikan rainbow kurumoi (M elanotaenia parva) hidup di habitat (alam) pada kisaran pH 6,8-8,5 (Tappin, 2010). Amonia $\left(\mathrm{NH}_{3}\right)$ selama penelitian 0,001-0,020 mg/L masih dalam kisaran aman bagi sintasan dan pertumbuhan larva. Tingginya nilai amonia dalam penelitian ini hanya pada akhir penelitian karena penyiponan (membuang kotoran) hanya dilakukan dua kali selama pemeliharaan. Konsentrasi amonia bebas sebaiknya tidak lebih dari 0,02 ppm. Jika kadar amonia bebas lebih dari $0,02 \mathrm{mg} / \mathrm{L}$, perairan bersifat toksik bagi beberapa jenis ikan (Effendi, 2003). Menurut

Tabel 4. Sintasan dan pertumbuhan larva rainbow kurumoi (M elanotaenia parva)

Table 4. Suvival rate and growth of larvae rainbow kurumoi (Melanotaenia parva)

\begin{tabular}{lccccc}
\hline \multicolumn{1}{c}{ Parameter } & \multicolumn{5}{c}{ Dosis pupuk (g)/ Fertilizer dosages (g) } \\
\cline { 2 - 6 } \multicolumn{1}{c}{ Parameter } & A.0 kontrol (control) & B.5 & C.10 & D.15 & E.20 \\
\hline Sintasan (Survival rate) (\%) & $46,67 \pm 3,21^{\mathrm{c}}$ & $71.67 \pm 3.22^{\mathrm{a}}$ & $74.00 \pm 4.36^{\mathrm{a}}$ & $80.67 \pm 6.66^{\mathrm{ab}}$ & $84.33 \pm 3.79^{\mathrm{b}}$ \\
Bobot (W eight) (g) & $0.030 \pm 0.017^{\mathrm{a}}$ & $0.031 \pm 0.015^{\mathrm{a}}$ & $0.036 \pm 0.014^{\mathrm{b}}$ & $0.040 \pm 0.013^{\mathrm{b}}$ & $0.048 \pm 0.012^{\mathrm{b}}$ \\
Panjang total (Total Length) (cm) & $1.44 \pm 0.15^{\mathrm{a}}$ & $1.54 \pm 0.17^{\mathrm{a}}$ & $1.55 \pm 0.16^{\mathrm{b}}$ & $1.57 \pm 0.15^{\mathrm{b}}$ & $1.67 \pm 0.15^{\mathrm{b}}$ \\
Panjang standar (Standard length) (cm) & $1.21 \pm 0.13^{\mathrm{a}}$ & $1.31 \pm 0.16^{\mathrm{a}}$ & $1.34 \pm 0.14^{\mathrm{b}}$ & $1.40 \pm 0.13^{\mathrm{b}}$ & $1.44 \pm 0.13^{\mathrm{b}}$ \\
\hline
\end{tabular}

Keterangan: Nilai dalam baris diikuti dengan huruf yang sama menunjukkan tidak berbeda nyata $(P>0,05)$

Remarks: The values in row followed by the same letter indicates not significantly different $(P>0.05)$ 
Tabel 5. Hasil analisa kualitas air selama 30 hari

Table 5. Results of water quality analysis for 30 days

\begin{tabular}{cccccc}
\hline $\begin{array}{c}\text { Perlakuan pupuk } \\
\text { Fertilizer treatment } \\
\mathbf{( g / 4 0 ~ L )}\end{array}$ & \multicolumn{5}{c}{ Nilai parameter kualitas air (Water quality parameter value) } \\
\cline { 2 - 7 } & $\begin{array}{c}\text { Suhu } \\
\text { Temperature }\left(\mathbf{~}^{\mathbf{C}} \mathbf{C}\right)\end{array}$ & $\begin{array}{c}\text { Oksigen } \\
\text { Oxygen }(\mathbf{m g} / \mathbf{L})\end{array}$ & $\mathbf{p H}$ & $\begin{array}{c}\text { Amonia } \\
\text { Ammonia }(\mathbf{m g} / \mathbf{L})\end{array}$ & $\begin{array}{c}\text { Kesadahan } \\
\text { Hardness }(\mathbf{m g} / \mathbf{L})\end{array}$ \\
\hline 0 & $24.20-29.00$ & $3.8-4.80$ & $6.20-6.90$ & $0.001-0.013$ & $33.2-49.2$ \\
5 & $24.02-29.01$ & $3.8-4.20$ & $6.21-7.00$ & $0.001-0.017$ & $33.0-49.2$ \\
10 & $24.01-29.00$ & $3.9-4.70$ & $6.23-7.02$ & $0.001-0.018$ & $33.0-59.5$ \\
15 & $24.05-29.00$ & $3.9-4.91$ & $6.22-7.04$ & $0.001-0.019$ & $33.2-59.9$ \\
20 & $24.05-29.03$ & $3.9-4.91$ & $6.24-7.40$ & $0.001-0.020$ & $33.9-61.6$ \\
\hline
\end{tabular}

Tappin (2010), kisaran kesadahan di habitat alam 50$250 \mathrm{mg} / \mathrm{L}$. Hasil penelitian di media kisaran kesadahan 43,9-61,6 mg/L dalam hal ini sedikit rendah tetapi masih dapat ditoleransi oleh larva karena hanya dalam waktu satu bulan pemeliharaan. Untuk larva nilai kesadahan sedikit lebih rendah tidak menjadi kendala, kecuali pembesaran benih sebaiknya dikondisikan pada kesadahan $>50 \mathrm{mg} / \mathrm{L}$.

\section{KESIMPULAN}

Penyedian pakan alami yang terbaik pupuk kotoran ayam dosis $20 \mathrm{~g} / 40 \mathrm{~L}$ dengan kelimpahan plankton 58.300 ind./L, sintasan larva $84,33 \pm 3,79 \%$ dan pertumbuhan (bobot $0,048 \pm 0,012 \mathrm{~g}$, panjang total $1,67 \pm 0,15 \mathrm{~cm}$ dan panjang standar $1,44 \pm 0,13 \mathrm{~cm})$ $(P<0,05)$.

\section{UCAPAN TERIMA KASIH}

Penulis mengucapakan terima kasih kepada Pak Kadurusman (APSOR), IRD-Perancis, Dr Sudarto, dan Gigih Wibawa (BRBIH Depok) yang telah melakukan ekspedisi ikan rainbow kurumoi ke Papua.

\section{DAFTAR ACUAN}

Asriyana \& Yuliana. (2012). Produktivitas Perairan. Bumi Aksara, $278 \mathrm{hlm}$.

Astiani, F., Dawiyanti, I., \& Mellisa, S. (2016). Pengaruh media kultur yang berbeda terhadap laju pertumbuhan dan biomassa Spirulina sp. Jurnal Budidaya Perairan, FKP Univ, Syiah Kuala Banda Aceh. ISSN 2529-6395 Nov. 2016, I(3), 441-447.

Boyd, C.E. (1990). Water quality management in warm fish pond. University Aqriculture Experiment Station. Alabama.

Effendi, H. (2003). Telaah Kualitas Air bagi Pengelolaaan Sumberdaya dan Lingkungan Perairan. Jurusan MSP FPIK IPB. Bogor, $258 \mathrm{hlm}$.
Insan, I. (2011). Pemeliharaan benih ikan balashark (Balantiocheilus melanopterus) dengan peningkatan kesuburan kolam. Jurnal Riset Akuakultur, 6(3), 413-423.

IUCN. (2016). The IUCN red list of threatened species. Melanotaenia parva (Lake Kurumoi rainbowfish). (http://www.iucnredlist.org/apps/redlist/ details/13072/0.html), 17 September 2016.

ITIS.gov. (2018). Brachionus sp. classification.https:// itis.gov/servlet/SingleRpt/SingleRpt/ search_topic $=$ TSN\&search_value $=58435 \#$ null. Diakses pada September 2018.

Kadarini. T., Nur, B., Nurhidayat, Sholichah, L., Zamroni, M., \& Wibawa, G.S. (2012). Petunjuk teknis budidaya ikan hias rainbow (M elanotaenia parva). Balai Penelitian dan Pengembangan Budidaya Ikan Hias, $36 \mathrm{hlm}$.

Kadarini, T., Zamroni, M., \& Erni K.P. (2013). Perkembangan awal larva ikan rainbow kurumoi (Melanotaenia parva) dari hasil pemijahan. Jurnal Riset Akuakultur, 8(1), 77-86.

Kadarusman, Sudarto, Paradis, E., \& Pouyaud, L. (2010). Description of Melanotaenia fasinensis, a new species of rainbowfish (Melanotaeniidae) from West Papua, Indonesia with comments on the rediscovery of $M$. ajamaruensis and the endangered status of M. parva. Cybium, 34(2), 207-215.

Lucas, J.S. \& Southgate, P.C. (2003). Aquaculture: Farming Aquatic Animals and Plants. Blacwell Publishing. Oxford, $502 \mathrm{pp}$.

Redjeki, S. (1999). Budidaya Rotifera (Brachionus plicatilis). Oseana, VolumeXXIV, ISSN0216-1877. Nomor2,1999:27-43.sumber:www.oseanografi. lipi.go.id.

Sachlan, M. (1982). Planktonologi. Fakultas Peternakan dan Perikanan. UNDIP. Semarang,177 hlm. 
Subandiyah, S., Hirnawati, R., \& Rohmy, S. (2011). Pengamatan pemeliharaan tiga jenis larva rainbow (asal Danau Kurumoi, Sungai Sawiat dan Sungai Gelap) dalam akuarium. Prosiding Seminar Nasional Perikanan 24-25 November 2011 STP. Kelompok Budidaya. ISSN: 1978 7278. Jakarta, hlm. 51-54.

Tappin, A.R. (2010). Rainbow Fishes: Their care \& keeping in capacity. Rainbow fishes@ptunesnet.com.av. Copyright.
Tappin, A.R. (2011). Home of rainbowfish. http:// rainbowfish.angfaqld.org.au/Parva.htm). (diakses 08/03/2012).

Utomo, N.B.P., W inarti, \& Erlina. (2005). Pertumbuhan Spirulina pletensis yang dikultur dengan pupuk in organik (Urea, TSP, dan ZA) dan kotoran ayam. Jurusan Budidaya Perairan Fakultas Perikanan dan IImu Kelautan IPB. Jurnal Akuakultur Indonesia, 4(1), 41-48. 